\title{
Bone Turnover and Vascular Calcification
}

Pei-Chen Wu${ }^{1}$, Cai-Mei Zheng ${ }^{2}$, Min-Tser Liao ${ }^{3}$, Chia-Chao Wu ${ }^{4}$, Kuo-Cheng Lu ${ }^{5}$ and Wen-Chih Liu $6^{*}$

${ }^{1}$ Department of Internal Medicine, Division of Nephrology, Da Chien General Hospital, Miaoli County, Taiwan

${ }^{2}$ Department of Internal Medicine, Division of Nephrology, Shuang Ho Hospital, Taipei Medical University, Taipei, Taiwan

${ }^{3}$ Department of Pediatrics, Taoyuan Armed Forces General Hospital, Taoyuan, Taiwan

${ }^{4}$ Department of Medicine, Division of Nephrology, Tri-Service General Hospital, National Defense Medical Center, Taipei, Taiwan

${ }^{5}$ Department of Medicine, Division of Nephrology, Cardinal Tien Hospital, School of Medicine, Fu-Jen Catholic University, New Taipei City, Taiwan

${ }^{6}$ Department of Internal Medicine, Division of Nephrology, Yonghe Cardinal Tien Hospital, New Taipei City, Taiwan

*Corresponding author: Wen-Chih Liu, Department of Internal Medicine, Division of Nephrology, Cardinal Tien Hospital, Yonghe Branch, 80 Zhongxing St., Yonghe Dist., New Taipei City 234, Taiwan, Fax: +886-2-29218270; E-mail: wayneliu55@gmail.com

Rec date: Apr 23, 2014, Acc date: May 28, 2014, Pub date: June 05, 2014

Copyright: (c) 2014 Wu PC, et al. This is an open-access article distributed under the terms of the Creative Commons Attribution License, which permits unrestricted use, distribution, and reproduction in any medium, provided the original author and source are credited.

\begin{abstract}
The impaired bone mineral metabolism followed byVascular Calcification (VC) will be presentat the beginning stage of Chronic Kidney Disease (CKD). VC can be considered as two major types, which are intimal calcification, associated with atherosclerosis, and medial calcification that involves damaged vascular smooth muscle cells (VSMCs), which leads to increase vascular stiffness and decrease vascular elasticity. Many factors control the mechanisms, and they are imbalances in serum calcium and phosphate, systemic inflammation, hyperparathyroidism, increased matrix degradation, VSMC apoptosis, decreased matrix glutamate protein, etc. These will make VSMCs Trans differentiation to phenotypic osteoblastic cells. In addition, patients with CKD usually have bone turnover problems. For a high turnover status, secondary hyperparathyroidism increases calcium and phosphate release from the bone, but for a low turnover status in a dynamic bone disorder, circulating phosphate and calcium cannot enter the bone to cause serum calcium and phosphate levels to frequently maintain at high levels. This is caused by the fact that the bone can no longer buffer the increases in phosphate and calcium load, and these conditions will cause the possibility of VC. Interestingly, the VC process will secrete sclerostin, a hormone that may act not only locally in the artery wall to reduce mineralization but also destroy bone mineralization. These problems will lead to reduced bone mass with a cycle between bone turnover and VC that only leads to problems. This article will describe the complex relationship between the rate of bone turnover and VC in CKD.
\end{abstract}

Keywords: Bone turnover; Vascular calcification; Bone remodeling; Wntsignaling

\section{Introduction}

Physiological bone remodeling is a lifelong and highly coordinated process of bone resorption and formation. It involves continuous removal of old bone, replacement with a newly synthesized proteinaceous matrix, and subsequent mineralization of the matrix to form new bone. Bone remodeling is starting with bone resorption and then bone formation. The resorption and formation is essential for repair of micro-fractures and to modify the bone structure as a response to stress or other forces. Remodeling is the replacement of bone without changing its shape. However, maintaining mineral homeostasis is another essential role of bone remodeling [1]. Generally speaking, bone turnover occurs in both cortical and trabecular bone with a relative higher turnover rate in trabecular bone. Bone turnover processes basically start with osteoclast activation.

At the onset of CKD, the systemic mineral metabolism and bone composition start to change. This alteration is known as CKD-MBD. The greater the decrease in renal function, the worse the progression of CKD-MBD. It is well known that bone turnover disorder is the most common complication of CKD-MBD. The Kidney Disease: Improving Global Outcomes (KDIGO) defined the term CKD-MBD as a broader systemic disorder of mineral and bone metabolism that occurs as a result of CKD [2]. CKD-MBD is characterized by the following: (1) abnormalities of calcium, phosphorus, parathyroid hormone (PTH), or vitamin D metabolism; (2) abnormalities in bone turnover, mineralization, volume linear growth, or strength; (3) vascular or other soft-tissue calcification [2].

\section{Normal bone remodeling}

In 1990, Frost defined bone remodelingasa complex process by which old bone is continuously replaced by new tissue so that remodeling brings about bone adaption to mechanical burden and stress [3]. For adults, bone remodeling includes four consecutive phases: resorption, reversal, formation and mineralization.

\section{Resorption}

It begins with the relocation of partially differentiated mononuclear preosteoclasts, derived from hematopoietic stem cells, on the bone surface where they form multinucleated osteoclasts. The ruffled border of osteoclast secrets and synthesizes lysosomal enzymes to decompose bone minerals and fragments of collage. Some of the collagen is digested into its smallest particles aspyridinoline and deoxypyridinoline residues. 


\section{Reversal}

It is a phase when mononuclear cells appear on the bone surface to help new osteoblasts adhere to resorbed surface and may provide signals for osteoblast differentiation and relocation. Osteopontin may play a key protein at the reversal site [4].

\section{Formation}

This phase is initiated by osteoblasts, differentiated from multipotent mesenchymal stem cells, laying down in groups on the resorbed bone surface [5]. Osteoblasts synthesize new collagenous organic matrix and regulate mineralization of matrix by releasing small, membrane bound matrix vesicles that concentrate calcium and phosphate and enzymatically destroy mineralization inhibitors such as pyrophosphate or proteoglycans [6]. They synthesize type I collagen and other proteins as osteocalcin to form osteoid extracellularly, then bone mineralization occurs [7]. The serum concentration of bonespecific alkaline phosphatase and osteocalcin reflect the cellular activity of osteoblasts [8-10].

\section{Mineralization}

It starts about two weeks after the osteoid newly formed. Bone mineralization is a well regulated process for accumulation of matrix molecules, which are produced by osteocytes and are piled up in precise amounts within the fibrous matrix. For adult people, the time of resorption is probably for 2 weeks, the reversal phase may last up to 4 or 5 weeks, while formation can continue for 4 months [5]. Usually, a bone structural unit to become fully mineralized will take several years.

\section{The Communication between Osteoclast and Osteoblast}

\section{Influence of osteoblast on osteoclast}

The bone remodeling process occurs through the action of RANK/ RANKL /OPG (receptor activator of nuclear factor kappa /receptor activator of nuclear factor kappa B ligand /osteoprotegerin) system. RANK, a type I membrane protein on the surface of osteoclast cells, is involved in osteoclast cell stimulation when bound with RANKL produced by osteoblasts [11]. RANK L/RANK signaling not only regulates the formation of multinucleated osteoclast cells from their precursors, but also influences their activation and survival during normal bone remodeling and in a variety of pathologic conditions [12]. OPG, the other protein secreted from osteoblast cells, is a potent inhibitor of osteoclast differentiation and protects the skeleton from excessive bone resorption by acting as a decoy receptor for RANK L and preventing RANK L from binding to its receptor, RANK [11]. Thus, the RANK L/OPG ratio is a significant determinant of bone formation.

This RANK/RANK L /OPG system is affected by hormones (such as: PTH, calcitriol, sex steroid, and glucocorticoids), cytokines, interleukins, etc. Increased PTH levels increase the quantity of osteoclasts and osteoblasts [13]. Calcitriol enhances calcium and phosphorus absorption from digestive track to help bone mineralization [14]. Both estrogen and androgen affect bone remodeling process as well. Estrogen, for example, not only act onosteoblastic lineage, but also influence on lineage, including osteoclast precursors, mature osteoclasts, and lymphocytes [15].
Glucocorticoid-induced osteoporosis may induce apoptosis of osteoblasts and osteocytes [16]. RANKL/RANK interaction provides essential signals to osteoclast progenitors, leading to osteoclast differentiation, an important step in osteoclastogenesis, and bone resorption. This process can be blocked by OPG, a decoy receptor for RANKL that protects against bone resorption and extensive deterioration [17].

\section{Influence of osteoclast on osteoblast}

Sema4D, a new signaling between osteoclast and osteoblast found by Negishi-Koga et al. [18], secreted by osteoclasts functions as a ligand to activate downstream of RhoA by binding its receptor, Plexin$\mathrm{B} 1$, on osteoblasts, thus suppressing the differentiation of osteoblast. Their study demonstrated that further RANK L-induced osteoclasto genesis will also induce osteoclasts highly express Sema4D at the same time [18]. In turn, producing more Sema4D to inhibit osteoblast differentiation serves as a negative feedback loop to balance the activity of osteoclasts and osteoblasts.

\section{Influence of osteocyte on osteoblast (Wnt signaling)}

Canonical Wnt signaling is a molecular pathway known to be essential for the regulation of bone physiology. During bone remodeling, the osteocyte will secrete sclerostin, and Dickkopf-related protein-1 (DKK-1) which may inhibit osteoblast differentiation and maturation through the inhibition of Wnt signaling [19].

\section{Influence of resorted bone matrix on osteoblast}

In addition, the active transforming growth factor- $\beta 1$ (TGF- $\beta 1$ ) and insulin-like growth factor-1 (IGF-1), secreted from bone matrix during bone resorption process, promotes directly the migration of bone marrow mesenchymal stem cells that form pre-osteoblasts and functions as a primary coupling factor in bone remodeling[20, 21]. In fact, the TGF- $\beta 1$ and IGF-1matricellular couples of bone resorption and formation and it is also signaling between progenitors. For example, RANKL present on the osteoblastic cell surface binds its cell membrane receptor RANK on osteoclast progenitors to stimulate osteoclastogenesis [22].

\section{Bone Turnover in CKD}

\section{The effects of uremic toxin}

In addition, $\mathrm{CKD}$ patients accumulate uremic substances in their body because of impaired kidney function. These uremic substances, called uremic toxins (UTx), have been reported to injure various organs. Indoxyl sulfate (IS) is one of the uremic toxins, and is derived from tryptophan. It is excreted mainly from the proximal renal tubules into urine through organic anion transporter 1 (OAT1) and organic anion transporter 3 (OAT3) channel [23]. Decreased renal clearance as occurs chronic renal failure will increase IS levels in the blood, so levels are approximately 30 times higher in patients with CKD stage 4-5 (not yet on dialysis) patients, and 80 times higher in patients before initiation of dialysis than in healthy persons [24].

Mozar et al. [25] confirmed that IS directly inhibits osteoclast differentiation and activity. Furthermore, Kim et al. illustrated that IS inhibits osteoblast differentiation and induces apoptosis via the caspase (cysteine asparate protease) pathway $[23,26]$. IS may deteriorate the outcomes of low bone turnover diseases and attenuate 
the chemical composition of bone in patients with CKD. Oral administration of the indole-absorbing agent, AST-120 prevents the progression of $\mathrm{VC}[27]$ and improves the low bone turnover status in patients with CKD [28].

\section{The Effects of PTH}

\section{The effects of high PTH}

In CKD patients, the effect of high levels of PTH on bone results in the high-turnover bone disease, such as: osteitis fibrosa, with excessive osteoclastic bone resorption and bone marrow fibrosis [29].

\section{The effects of low PTH}

In contrast, low-turnover bone disease is common in patients with $\mathrm{CKD}$, especially in dialysis patients under high dose of active vitaminD3 [30].Osteomalacia, aluminum-induced bone disease, and a dynamic bone disease are all low-turnover bone diseases. Osteomalaciais also related to reduce active vitamin $\mathrm{D}$ and chronic metabolic acidosis [31]. Aluminum ingestioncauses the reducing both osteoclast resorption and osteoblast formation surfaces. Moreover, chronic low dose aluminum exposure with high intake of vitamin D reduces PTH synthesis and secretion in dialysis patients, who may present with a dynamic bone disease rather than osteomalacia [32].

\section{Vascular Calcification in CKD}

In patients with $\mathrm{CKD}$, cardiovascular disease remains the leading cause of morbidity and mortality. Examination of CKD patients who have VC reveals two different but overlapping arterial pathologies; atherosclerosis and arteriosclerosis [33]. The presence of VC in the dialysis population is multifactorial, but hyperphosphatemia and over calcium load (ingested calcium-containing oral phosphate binders) are the main contributions to VC. Especially, hyperphosphatemia stimulatesosteogenic/chondrogenic differentiation, vesicle release, apoptosis of VSMC, loss of inhibitors, and extracellular matrix degradation to drive VC [34].

\section{Atherosclerosis and Arteriosclerosis (Table 1)}

Inflammation, thickening, and calcification on the intimal layer of vascular is called atherosclerosis [35] that occurs preferentially in medium-sized arteries and usually results in occlusion. By contrast, arteriosclerosis is calcification of the media layer, which usually leads to thickening of the medial layer and is most commonly found in elastic arteries to increased arterial stiffness [36], and may lead to left ventricular hypertrophy [37]. Arteriosclerosis, common in patients with diabetes, renal failure, and advanced aging [38,39], is not principally an inflammatory process but associated with apoptosis of VSMCs [40].

\begin{tabular}{|c|c|c|}
\hline Layer of vascular wall & Intima & Media \\
\hline Features of histology & $\begin{array}{l}\text { Atherosclerosis } \\
\text { lipid-laden plaques } \\
\text { micro-inflammation of the atherosclerotic plaque. } \\
\text { Predominantly in medium-sized arteries } \\
\text { aggregates of calcium sedimentations } \\
\text { patchy and focal in distribution, }\end{array}$ & $\begin{array}{l}\text { Arteriosclerosis } \\
\text { deeper layer of the arterial wall } \\
\text { Linear sedimentations on elastic lamellae. } \\
\text { Diffuse contiguous fashion. } \\
\text { extracellular matrix deposition } \\
\text { fibroelastic intimal thickening } \\
\text { hydroxyapatite and whitlockite deposition }\end{array}$ \\
\hline Associated clinical symptoms & $\begin{array}{l}\text { Plaques rupture } \\
\text { Myocardial Infraction, or } \\
\text { Cerebrovascular accident }\end{array}$ & $\begin{array}{l}\text { Vascular stiffness: } \\
\text { Heart failure, } \\
\text { Left ventricular hypertrophy } \\
\text { Cardiac Valve Calcification, } \\
\text { Monckeberg's sclerosis }\end{array}$ \\
\hline Risk factors & $\begin{array}{l}\text { Lipid, macrophages, inflammation } \\
\text { HCVD, DM, Oxidative stress }\end{array}$ & $\begin{array}{l}\text { Elastin degradation, hyperphosphatemia, } \\
\text { Hypercalcemia } \\
\text { Dialysis vintage } \\
\text { Decreased inhibitors of calcification }\end{array}$ \\
\hline Plain radiography & Spotty calcification & Linear tram-track calcification \\
\hline
\end{tabular}

Table 1: Two Types of Vascular Calcification

Atherosclerosis is patchy and focal in its distribution but arteriosclerosis affects the media tunica. On plain radiographs, atherosclerosis and arteriosclerosis can usually be distinguished as spotty calcifications versus linear tram-track calcifications [41].

\section{Pathophysiology of VC}

Hyperphosphatemia, a common problem in CKD, can enhance the sodium-dependentphosphate transporter PIT-1 and contribute to increased calcification [42]. This calcification is not simply the result of calcium and phosphorus precipitation from the circulation [43]. It can induce calcification by up-regulating mRNA expression for osteogenic factors including BMP 2, Cbfa1/Runx2, Msx2, and osteocalcin [44]. Osteoblasts and VSMCs have a common mesenchymal origin. Core binding factor-1 (Cbf 1 ) is thought to trigger mesenchymal cell-to-osteoblast transformation [45] via causing the expression of major bone matrix components such as osteocalcin, type I collagen, and osteopontin (OPN). Hyperphosphatemia also 
leads the activation of the $\mathrm{Wnt} / \beta$-catenin signaling pathway by the translocation of $\beta$-catenin into the smooth muscle cell nucleus, increasing the expression of direct target genes such as cyclin D1, axin 2, and VCAN/versican [44]. Both BMP and Wnt signaling proteins regulate bone mass by promoting osteogenesis by stimulating Runx2 gene expression [44] but the molecular interactions between these pathways in osteogenesis and bone formation are not completely defined [46]. Therefore, hyperphosphatemia can induce the formation of bone matrix vesicles, which containapatite and calcifying collagen fibrils on the surface of VSMCs [47]. Furthermore, these vesicles almost certainly act as early nucleation sites for calcification in the vascular wall [44].

In addition, there are still many factors impacting $\mathrm{VC}$, which is a precise complex process. Recently, a mounting evidence suggests that VC process is similar to mineralization in bone [48]. Many experts pointed out the transformation of VSMCs to an osteogenic/ chondrogenic phenotype that promotes the release of the vesicular structures. The calcification is initiated by these osteoblast-phenotype cells then lay down an extracellular matrix of collagen and noncollagenous proteins to make matrix vesicles or apoptotic bodies, which contain hydroxyapatite [49]. The calcification process includes active and passive processes. The active process is the mineralization in these structures is stimulated by osteoblastic proteins. In contrast, the passive process involves mineral precipitation from the extracellular fluid surrounding the VSMCs in the vascular walls [50]. Both the up regulation of these promoters (such as: hyperphosphatemia, osteopontin, osteonectin, alkaline phosphatase, type I collagen, and bone morphogenic protein (BMP)-2) [51-53] and the down regulation of these inhibitors (such as:fetuin A, matrix gla protein, and pyrophosphate) [54-56] will enhance VC. In CKD patients, hyperphosphatemia is a major important contributor to VC [57].

\section{Linkage Between Bone Turnover and VC in CKD}

Patients with CKD may present with dysregulation of RAKN/ RANKL/OPG system resulted in either high or low bone turnover disorders. Both high and low bone turnover disorders may induce vascular calcification. The calcified vessel (phenotypic osteoblast/ osteocyte in calcifying vasculature) may secrete FGF23 and Wnt inhibitors such as sclerostin, DKK-1 and secreted frizzled-related protein to prevent further VC. However, all of them may fight back the inhibition of bone formation resulting in fragile bone.

\section{RANK/RANKL/OPG and VC}

More and more researchers now approve that $\mathrm{VC}$ is an actively regulated process with stimulative and suppressive factors, just like bone remodeling process [58]. It is clear that impaired bone metabolism plays an important role in the development of VC [50]. As previous mention, there are three key elements that influence the bone formation process: RANK, RANKL, and OPG. In addition, mounting evidence suggests that the RANK/RANKL/OPG triad is involved in bone metabolism, and may be important in VC [59,60]. Experts found OPG, RANKL, and RANK exists in extra osseous calcifications such as atherosclerotic calcifications and cardiac valve calcifications. Also, the varied stages of CKD present the relative different expression levels of RANK/RANKL/OPG [61,62].

Panizo et al. [63] stated that RANKL directly increased VSMC calcification by binding to RANK and stimulating BMP4 secretion by the alternative NF-kB pathway. Thus, RANK/RANKL may be crucial in stimulating VC, whereas OPG inhibits VC. OPG appears to be the molecular link between bone resorption and VC, which may help recognize the close relationship between atherosclerosis and osteoporosis in postmenopausal women [64]. Estrogen, as osteoblast stimulator and osteoclast inhibitor, influences on TGF- $\beta$, which also stimulates calcitonin production as well. The other functions of estrogen are decreasing the level of pro-inflammatory cytokines and increasing OPG gene expression in osteoblast. It is believed that the postmenopausal women with low estrogen concentration will increase bone resorption. Because the higher level of proinflammatory cytokines lessens the activity of endothelial nitric oxide synthase (eNOS) to limit the production of nitric oxide that can stimulate osteoblasts and block osteoclasts [65]. Therefore, prescribing postmenopausal women with estrogen is a benefit to reduce vascular calcification [66,67]. Shargorodsky et al. [68] identified that serum OPG level is an independent predictor of early cardiovascular events in osteoporotic postmenopausal women.

\section{Altered bone turnover (high or low) on VC in patients with CKD}

The bone and the vascular system have a multifaceted relationship. Both have similar and mutual changes in mineralization, a situation called the bone-vascular axis [69]. It was continuously indicated that the connection between bone osteoporosis and VC was because of a significant negative correlation between bone mineral density and aortic calcification [70]. However, this correlation is poorly understood and underlying association has not yet been wellcharacterized. Besides, CKD is usually in low bone turnover status, which reduces the ability of bone buffering mineral metabolites such as calcium and phosphate. The excess calcium and phosphate, unable to enter bone, leads the advance of promoting epromote $\mathrm{VC}$ in circulation [71]. Hence, low bone turnover is frequently associated with coronary artery calcium (CAC) score progression in hemodialysis patients [72].

Some studies also revealed that low bone turnover or mineralized bone mass is inversely related to the degree of coronary artery calcification and vascular stiffness [73]. Rodriguez-Garcia et al. [74] analyzed hemodialysis patients and found that calcification in the large-or medium-size- artery is associated with a higher possibility of vertebral fractures. As well, this study showed that both VC and vertebral fractures were associated with increased mortality among research samples [74].

The relationship between low bone turnover and VC remains unclear [75]. Recent publications examining low or even high bone turnover, discovered that VC is not influenced by bone turnover itself, but is related to situations where bone resorption is greater than bone formation (Figure 1). These researchers approved that $\mathrm{VC}$ can occur at any level of bone turnover [75]. As described before, serum phosphate may be one of the connections between bone turnover and VC. When bone turnover is low, as with a dynamic bone, the amount of interchangeable calcium and phosphate is decreased, leading to higher concentrations in blood serum associated with intake. Additionally, bone resorption is more prominent than bone formation, interfering with the buffering function of the skeleton for extra phosphate. Oppositely, when high bone turnover is present as in secondary hyperparathyroidism, a lot of phosphate is released from bone and, again, the reservoir function of the skeleton is ruined [50]. Therefore, the correcting the balance in bone turnover, either high or low, will protect against the progression of $\mathrm{VC}$ [72]. 


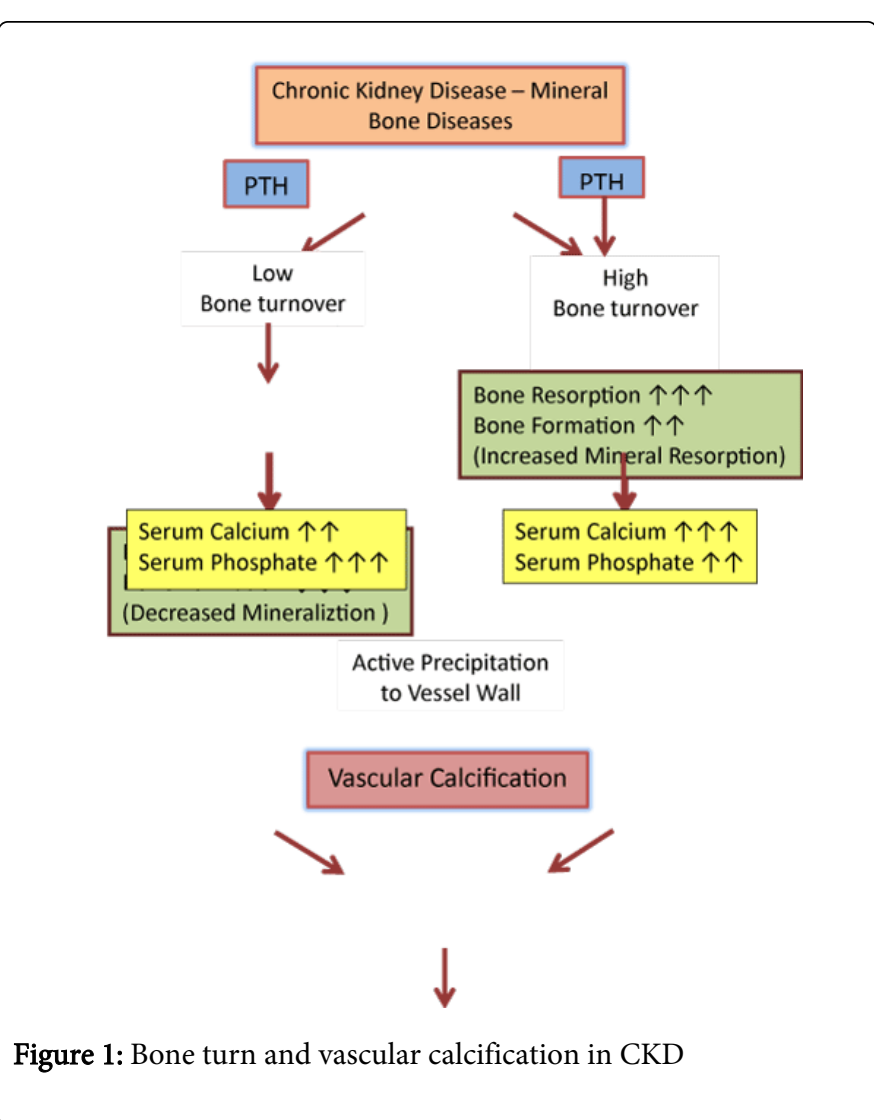

Basically, bone cells in CKD were less vitality than in normal. Thus, low bone turnover is the innate character of CKD. In the presence of high serum PTH levels, high PTH will overcome the indolent bone cells and present with high turnover bone disease with a characteristic of relative higher bone resorption than bone formation. The high turnover status in SHPT will induce an increased bone demineralization which will increase release $\mathrm{Ca}$ and $\mathrm{Pi}$ from bone into circulation. In contrast, CKD patients overtreatment with Ca-salts, VDRA or aluminum may develop low turnover bone disorders and low serum PTH levels. In low bone turnover status, the decreased bone mineralization leading difficult of $\mathrm{Ca}$ and $\mathrm{Pi}$ entry into bone resulting increase of serum $\mathrm{Ca}$ and $\mathrm{Pi}$. Both high and low turnover bone disorders have a relatively higher degree of bone resorption than bone formation which may contribute the elevation of serum $\mathrm{Ca}$ and $\mathrm{Pi}$ and aggravate vascular calcification/ossification.

Calcified vessel affect bone metabolism through Wnt signaling inhibitors VC and impaired bone metabolism are the common and important reasons of mortality and morbidity in patients with CKD or osteoporosis [2]. The Wnt signaling pathway is a complicated network of several proteins that impact normal physiologic bone formation metabolism [76]. The consequence of Wnt signaling in bone is mediated by stimulation of stem cells and proliferation of preosteoblasts, induction of osteoblastogenesis, inhibition of osteoblast and osteocyte apoptosis, and attenuation of osteoclastogenesis [77,78]. Thus, the physiological mechanisms of Wnt signaling lead to both formation and anti-resorption benefits at the same time [79]. The effect of Wnt signaling depends on a trans membrane receptor complex composed of the frizzled receptor and the low-density lipoprotein receptor-related protein (LRP)-5 or LRP-6 co-receptors [77,78].
Recent evidence supports the concept that there are inhibitors associated with the Wnt signaling pathway, such as sclerostin, secreted frizzled proteins 2 and 4, and DKK-1, that enhance osteoclast function and link VC and bone loss [80,81] (Figure 2). Pinzone et al. [82] pointed out that DKK-1 has two differing roles in influencing bone mass, which are increasing the osteolytic activity and decreasing osteoblast differentiation. Tumor necrosis factor alpha (TNF- $\alpha$ ) stimulatesthe secretion of DKK1, which leads to decreased bone mass by inhibiting the prevention of mesenchymal stem cells (MSC)derived osteoblastogenesis and lowering OPG levels. When DKK-1 increases RANKL levels and raises RANKL/OPG ratio which promotes osteoclast activity and results in bone resorption [82].

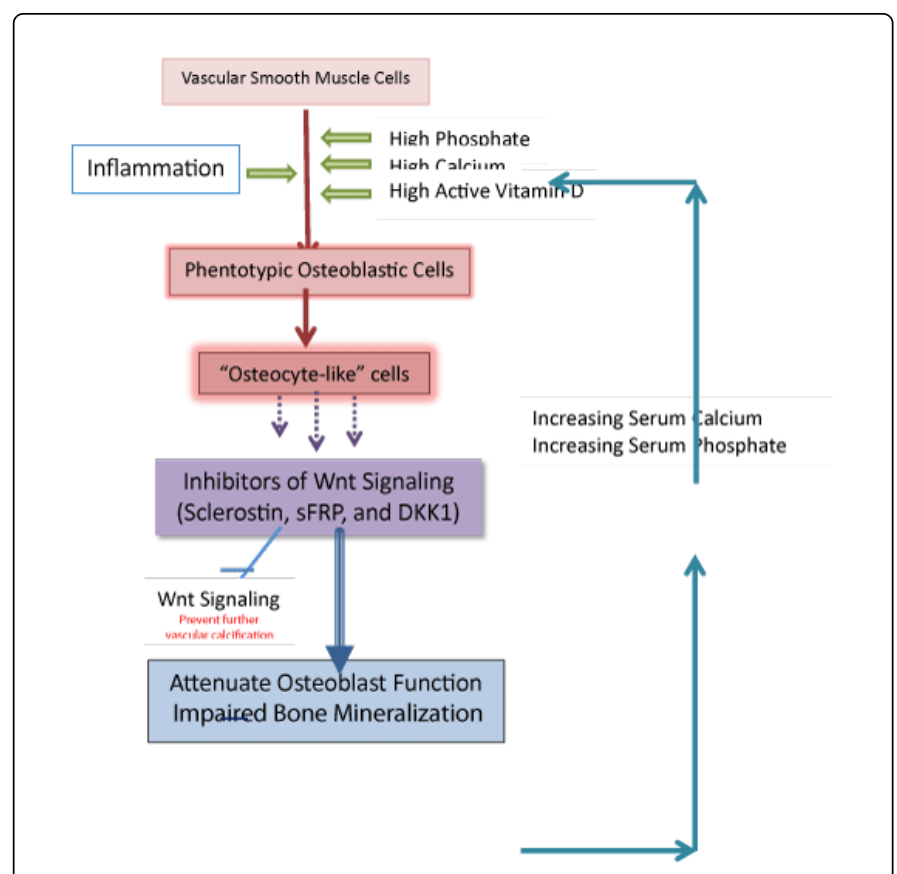

Figure 2: The effects of inhibitors of Wnt signaling

The phenotypic osteoblast/osteocyte in calcified vessels may secrete sclerostin (SOST), secreted frizzled-related protein (sFRP), and Dickkopf-related protein 1 (DKK1) which prevent the further calcified the victim vessel. The secreted SOST and SFRP will process an autocrine or paracrine effects on the inhibition of Wnt signalling on the osteogenic trans differentiation of VSMCs which will prevent further calcification of the vessel wall. As the secreted SOST and sFRP from calcified vessel may release into circulation, which may fight back inhibits Wnt signaling of osteoblast on bone. This inhibition of bone osteoblast reduced bone accretion and then turnover, which may also contribute to the elevation of serum phosphate and calcium. The increased serum phosphate and calcium further promote vascular calcification.

Sclerostin, a glycoprotein inhibitor of osteoblastogenesis, is secreted by osteocytes and travels through osteocyte canaliculi to the bone surface where it binds to LRP-5 and LRP-6 co-receptors. Consequently, sclerostin prevents frizzled proteins from colonizing on bone and blocks Wnt signaling to reduce osteoblastogenesis and bone formation [76]. Then, sclerostin may have a negative feedback role in osteoblasts signaling at the onset of osteoid mineralization $[19,83]$. Additionally, more recent evidence suggests that the Wnt signaling 
pathway not only plays an important role in bone metabolism, but is also involved in medial artery and aortic valve calcification [84-86].

Sclerostinis an important inhibitor in alkaline phosphatase activity [87]. In vascular and aortic valve calcification cases, sclerostin has also been shown to increase expression[86].The purpose of this up regulation of sclerostin or other Wnt inhibitors in vascular calcification is a feedback loop to slow down the calcification process of vascular [86].

Because sclerostin secreted from either the osteoid or the calcified vessel may spread to the circulation, Drake et al. [88] stated that bone marrow plasma and peripheral serum sclerostin levels were strongly correlated. Thus, sclerostin may be a significant communicator between bone and vascular soft tissue calcification [89]. Some evidence suggests that ageing, diabetes, male gender, and low PTH levels are all associated with high circulating sclerostin levels [90-92]. Particularly, sclerostin levels also increase with the progression of CKD and correlate inversely with histological parameters of bone turnover, and osteoblast number and function in hemodialysis patients [19]. Sclerostin spreads from the calcified vessel and may deteriorate bone structure and retard further mineralization $[86,89]$. This may clarify why VC is negatively associated with bone density and positively related to fractures [74,93]. Moreover, sclerostin may be a main mineralization regulator in VC [86] and impaired bone metabolism [94]. Therefore, it plays an important role in the bone-vascular axis $[50]$.

\section{Conclusions}

The patients with CKD-MBD usually have either low bone turnover rate or high rate, both of these two situations will promote VC. Furthermore, the bone turnover disorders and VC maycontribute the acceleration of morbidity and mortality in CKD. Many studies have suggested that VC, impaired bone turnover and increased bone fracture risk were interrelated closely. However, it ismore clear that $\mathrm{VC}$ is not strongly related to bone turnover, but the real cause of VC is bone resorption in excess of boneformation, which can occur at any rate of turnover.

Currently, the Wnt signaling pathway is known to play an important role in bone homeostasis and VC. Besides, the increased expression of sclerostin, sFRP, DKK1, inhibitors of Wnt signaling, is approved to retard the transformation of VSMC into osteoblasts during VC. However, the higher circulating sclerostin level will inhibit Wnt signaling in bone to result in lowering bone turnover rates and increases serum phosphate levels. High phosphate levels induce VSMC transforming to osteoblast-like cells and lead to produce sFRP. Wnt signaling also promotes VSMCs changing to osteoblasts. Those Wnt signaling inhibitors may not only reduce mineralization of the artery wall but also reduce bone mineralization. Thus, bone inhibition and VC will affect each other in harmful ways.

So, the most important methods to prevent soft tissue calcification are maintaining normal mineral metabolism and promoting bone health. In other words, to control serum phosphorus and serum calcium in the standard range through keeping up normal bone turnover rate may provide the greatest benefit to VC.

\section{Acknowledgement}

AlI authors declare that there is no conflict of interests regarding the publication of this review article.

\section{References}

1. Liu WC, Yen JF, Lang CL2, Yan MT3, Lu KC4 (2013) Bisphophonates in CKD patients with low bone mineral density. ScientificWorldJournal 2013: 837573.

2. Moe S, Drueke T, Cunningham J, Goodman W, Martin K, et al. (2006) Definition, evaluation, and classification of renal osteodystrophy: a position statement from Kidney Disease: Improving Global Outcomes (KDIGO). Kidney international 69: 1945-1953.

3. Frost HM (1990) Skeletal structural adaptations to mechanical usage (SATMU): 2. Redefining Wolff's law: the remodeling problem. Anat Rec 226: 414-422.

4. McKee MD, Nanci A (1996) Osteopontin at mineralized tissue interfaces in bone, teeth, and osseointegrated implants: ultrastructural distribution and implications for mineralized tissue formation, turnover, and repair. Microscopy research and technique 33: 141-164.

5. Hadjidakis DJ, Androulakis II (2006) Bone remodeling. Ann N Y AcadSci 1092: 385-396.

6. Anderson HC (2003) Matrix vesicles and calcification. CurrRheumatol Rep 5: 222-226.

7. Calvo MS, Eyre DR, Gundberg CM (1996) Molecular basis and clinical application of biological markers of bone turnover. Endocr Rev 17: 333-368.

8. Taylor AK, Lueken SA, Libanati C, Baylink DJ (1994) Biochemical markers of bone turnover for the clinical assessment of bone metabolism. Rheum Dis Clin North Am 20: 589-607.

9. Gomez B Jr, Ardakani S, Ju J, Jenkins D, Cerelli MJ, et al. (1995) Monoclonal antibody assay for measuring bone-specific alkaline phosphatase activity in serum. ClinChem 41: 1560-1566.

10. Garnero P, Delmas PD (1993) Assessment of the serum levels of bone alkaline phosphatase with a new immunoradiometric assay in patients with metabolic bone disease. J ClinEndocrinolMetab 77: 1046-1053.

11. Eissmann P, Evans JH, Mehrabi M, Rose EL, Nedvetzki S, et al. (2010) Multiple mechanisms downstream of TLR-4 stimulation allow expression of NKG2D ligands to facilitate macrophage/NK cell crosstalk. J Immunol 184: 6901-6909.

12. Boyce BF, Xing L (2007) Biology of RANK, RANKL, and osteoprotegerin. Arthritis Res Ther 9 Suppl 1: S1.

13. Mohler ER 3rd, Gannon F, Reynolds C, Zimmerman R, Keane MG, et al. (2001) Bone formation and inflammation in cardiac valves. Circulation 103: 1522-1528.

14. Weinstein RS, Underwood JL, Hutson MS, DeLuca HF (1984) Bone histomorphometry in vitamin D-deficient rats infused with calcium and phosphorus. Am J Physiol 246: E499-505.

15. Raisz LG (2005) Pathogenesis of osteoporosis: concepts, conflicts, and prospects. J Clin Invest 115: 3318-3325.

16. Weinstein RS, Jilka RL, Parfitt AM, Manolagas SC (1998) Inhibition of osteoblastogenesis and promotion of apoptosis of osteoblasts and osteocytes by glucocorticoids. Potential mechanisms of their deleterious effects on bone. The Journal of clinical investigation 102: 274-282.

17. RajamannanNM, Evans FJ, Aikawa E, Grande-Allen KJ, Demer LL, et al. (2011) Calcific aortic valve disease: not simply a degenerative process: A review and agenda for research from the National Heart and Lung and Blood Institute Aortic Stenosis Working Group. Executive summary: Calcific aortic valve disease-2011 update. Circulation 124: 1783-1791.

18. Negishi-Koga T, Shinohara M, Komatsu N, Bito H, Kodama T, et al. (2011) Suppression of bone formation by osteoclastic expression of semaphorin 4D. Nat Med 17: 1473-1480.

19. Cejka D, Herberth J, Branscum AJ, Fardo DW, Monier-Faugere MC, et al. (2011) Sclerostin and Dickkopf-1 in renal osteodystrophy. Clin J Am SocNephrol 6: 877-882.

20. Esmon CT (2004) The impact of the inflammatory response on coagulation. Thromb Res 114: 321-327.

21. Kassel KM, Owens AP 3rd, Rockwell CE, Sullivan BP, Wang R, et al. (2011) Protease-activated receptor 1 and hematopoietic cell tissue factor 
are required for hepatic steatosis in mice fed a Western diet. Am J Pathol 179: 2278-2289.

22. Badeanlou L, Furlan-Freguia C, Yang G, Ruf W, Samad F (2011) Tissue factor-protease-activated receptor 2 signaling promotes diet-induced obesity and adipose inflammation. Nat Med 17: 1490-1497.

23. Kim YH, Kwak KA, Gil HW, Song HY, Hong SY (2013) Indoxyl sulfate promotes apoptosis in cultured osteoblast cells. BMC PharmacolToxicol 14: 60 .

24. Osbourn DM, Weiss DJ, Lunte CE (2000) On-line preconcentration methods for capillary electrophoresis. Electrophoresis 21: 2768-2779.

25. Mozar A, Louvet L, Godin C, Mentaverri R, Brazier M, et al. (2012) Indoxylsulphate inhibits osteoclast differentiation and function. Nephrology, dialysis, transplantation: official publication of the European Dialysis and Transplant Association - European Renal Association 27: 2176-2181.

26. Nii-Kono T, Iwasaki Y, Uchida M, Fujieda A, Hosokawa A, et al. (2007) Indoxyl sulfate induces skeletal resistance to parathyroid hormone in cultured osteoblastic cells. Kidney Int 71: 738-743.

27. Goto S, Kitamura K, Kono K, Nakai K, Fujii H, et al. (2013) Association between AST-120 and abdominal aortic calcification in predialysis patients with chronic kidney disease. ClinExpNephrol 17: 365-371.

28. Iwasaki Y, Yamato H, Nii-Kono T, Fujieda A, Uchida M,et al. (2006) Administration of oral charcoal adsorbent (AST-120) suppresses lowturnover bone progression in uraemic rats. Nephrology, dialysis, transplantation: official publication of the European Dialysis and Transplant Association - European Renal Association 21: 2768-2774.

29. Spaulding CM, Young G (1997) Osteitisfibrosacystica and chronic renal failure. J Am Podiatr Med Assoc 87: 238-240.

30. Martin KJ, González EA (2007) Metabolic bone disease in chronic kidney disease. J Am SocNephrol 18: 875-885.

31. Coen G, Manni M, Addari O, Ballanti P, Pasquali M, et al. (1995) Metabolic acidosis and osteodystrophic bone disease in predialysis chronic renal failure: effect of calcitriol treatment. Miner Electrolyte Metab 21: 375-382.

32. Cannata-Andía JB (1998) Hypokinetic azotemicosteodystrophy. Kidney Int 54: 1000-1016.

33. Kjekshus J, Apetrei E, Barrios V, Böhm M, Cleland JG, et al. (2007) Rosuvastatin in older patients with systolic heart failure. N Engl J Med 357: 2248-2261.

34. Shanahan CM, Crouthamel MH, Kapustin A, Giachelli CM (2011) Arterial calcification in chronic kidney disease: key roles for calcium and phosphate. Circ Res 109: 697-711.

35. Wu M, Rementer C, Giachelli CM (2013) Vascular calcification: an update on mechanisms and challenges in treatment. Calcif Tissue Int 93: 365-373.

36. Moody WE, Edwards NC, Chue CD, Ferro CJ, Townend JN (2013) Arterial disease in chronic kidney disease. Heart 99: 365-372.

37. Cannata-Andia JB, Rodriguez-Garcia M, Carrillo-Lopez N, Naves-Diaz M, Diaz-Lopez B (2006) Vascular calcifications: pathogenesis, management, and impact on clinical outcomes. Journal of the American Society of Nephrology: JASN 17: S267-273.

38. Proudfoot D, Shanahan CM (2001) Biology of calcification in vascular cells: intima versus media. Herz 26: 245-251.

39. Lehto S, Niskanen L, Suhonen M, Ronnemaa T, Laakso M (1996) Medial artery calcification. A neglected harbinger of cardiovascular complications in non-insulin-dependent diabetes mellitus. Arteriosclerosis, thrombosis, and vascular biology 16: 978-983.

40. Shroff RC, McNair R, Skepper JN, Figg N, Schurgers LJ, et al. (2010) Chronic mineral dysregulation promotes vascular smooth muscle cell adaptation and extracellular matrix calcification. Journal of the American Society of Nephrology: JASN 21: 103-112.

41. LINDBOM A (1950) Arteriosclerosis and arterial thrombosis in the lower limb; a roentgenological study. ActaRadiolSuppl 80: 1-80.
42. Jono S, McKee MD, Murry CE, Shioi A, Nishizawa Y, et al. (2000) Phosphate regulation of vascular smooth muscle cell calcification. Circ Res 87: E10-17.

43. Shanahan CM, Weissberg PL, Metcalfe JC (1993) Isolation of gene markers of differentiated and proliferating vascular smooth muscle cells. Circ Res 73: 193-204.

44. Martinez-Moreno JM, Munoz-Castaneda JR, Herencia C, Oca AM, Estepa JC, et al. (2012) In vascular smooth muscle cells paricalcitol prevents phosphate-induced Wnt/beta-catenin activation. American journal of physiology. Renal physiology 303: F1136-1144.

45. Ducy P, Zhang R, Geoffroy V, Ridall AL, Karsenty G (1997) Osf2/Cbfa1: a transcriptional activator of osteoblast differentiation. Cell 89: 747-754.

46. Kamiya N, Kobayashi T, Mochida Y, Yu PB, Yamauchi M, et al. (2010) Wnt inhibitors Dkk1 and Sost are downstream targets of BMP signaling through the type IA receptor (BMPRIA) in osteoblasts. J Bone Miner Res 25: $200-210$.

47. Wada T, McKee MD, Steitz S, Giachelli CM (1999) Calcification of vascular smooth muscle cell cultures: inhibition by osteopontin. Circ Res 84: 166-178.

48. Moe SM, Chen NX (2008) Mechanisms of vascular calcification in chronic kidney disease. J Am SocNephrol 19: 213-216.

49. Mathew S, Tustison KS, Sugatani T, Chaudhary LR, Rifas L, et al. (2008) The mechanism of phosphorus as a cardiovascular risk factor in CKD. J Am SocNephrol 19: 1092-1105.

50. Cannata-Andia JB, Roman-Garcia P,Hruska K (2011) The connections between vascular calcification and bone health. Nephrology, dialysis, transplantation: official publication of the European Dialysis and Transplant Association - European Renal Association 26: 3429-3436.

51. Ahmed S, O'Neill KD, Hood AF, Evan AP, Moe SM (2001) Calciphylaxis is associated with hyperphosphatemia and increased osteopontin expression by vascular smooth muscle cells. American journal of kidney diseases: the official journal of the National Kidney Foundation 37: 1267-1276.

52. Boström K (2001) Insights into the mechanism of vascular calcification. Am J Cardiol 88: 20E-22E.

53. Chen NX, O'Neill KD, Duan D, Moe SM (2002) Phosphorus and uremic serum up-regulate osteopontin expression in vascular smooth muscle cells. Kidney Int 62: 1724-1731.

54. Schafer C, Heiss A, Schwarz A, Westenfeld R, Ketteler M, et al. (2003) The serum protein alpha 2-Heremans-Schmid glycoprotein/fetuin-A is a systemically acting inhibitor of ectopic calcification. The Journal of clinical investigation 112: 357-366.

55. Sweatt A, Sane DC, Hutson SM, Wallin R (2003) Matrix Gla protein (MGP) and bone morphogenetic protein-2 in aortic calcified lesions of aging rats. J ThrombHaemost 1: 178-185.

56. Koh N, Fujimori T, Nishiguchi S, Tamori A, Shiomi S, et al. (2001) Severely reduced production of klotho in human chronic renal failure kidney. BiochemBiophys Res Commun 280: 1015-1020.

57. Ott SM (2013) Therapy for patients with CKD and low bone mineral density. Nat Rev Nephrol 9: 681-692.

58. Boström KI, Rajamannan NM, Towler DA (2011) The regulation of valvular and vascular sclerosis by osteogenicmorphogens. Circ Res 109: 564-577.

59. Ndip A, Williams A, Jude EB, Serracino-Inglott F, Richardson S, et al. (2011) The RANKL/RANK/OPG signaling pathway mediates medial arterial calcification in diabetic Charcot neuroarthropathy. Diabetes 60: 2187-2196.

60. Papadopouli AE, Klonaris CN, Theocharis SE (2008) Role of OPG/ RANKL/RANK axis on the vasculature. HistolHistopathol 23: 497-506.

61. Heymann MF, Herisson F, Davaine JM, Charrier C, Battaglia S, et al. (2012) Role of the OPG/RANK/RANKL triad in calcifications of the atheromatous plaques: comparison between carotid and femoral beds. Cytokine 58: 300-306.

62. Steinmetz M, Skowasch D, Wernert N, Welsch U, Preusse CJ, et al. (2008) Differential profile of the OPG/RANKL/RANK-system in 
degenerative aortic native and bioprosthetic valves. J Heart Valve Dis 17: 187-193.

63. Panizo S, Cardus A, Encinas M, Parisi E, Valcheva P, et al. (2009) RANKL increases vascular smooth muscle cell calcification through a RANK-BMP4-dependent pathway. Circ Res 104: 1041-1048.

64. Karwowski W, Naumnik B, Szczepa $\AA$,ski M, MyÅıliwiec M (2012) The mechanism of vascular calcification - a systematic review. Med SciMonit 18: RA1-11.

65. Das UN (2002) Nitric oxide as the mediator of the antiosteoporotic actions of estrogen, statins, and essential fatty acids. ExpBiol Med (Maywood) 227: 88-93.

66. Mackey RH, Kuller LH, Sutton-Tyrrell K, Evans RW, Holubkov R, et al. (2005) Hormone therapy, lipoprotein subclasses, and coronary calcification: the Healthy Women Study. Arch Intern Med 165: 510-515.

67. Manson JE, Allison MA, Rossouw JE, Carr JJ, Langer RD, et al. (2007) Estrogen therapy and coronary-artery calcification. N Engl J Med 356: 2591-2602.

68. Shargorodsky M, Boaz M, Luckish A, Matas Z, Gavish D, et al. (2009) Osteoprotegerin as an independent marker of subclinical atherosclerosis in osteoporotic postmenopausal women. Atherosclerosis 204: 608-611.

69. Demer LL, Tintut Y (2008) Vascular calcification: pathobiology of a multifaceted disease. Circulation 117: 2938-2948.

70. Frye MA, Melton LJ 3rd, Bryant SC, Fitzpatrick LA, Wahner HW, et al. (1992) Osteoporosis and calcification of the aorta. Bone Miner 19: 185-194.

71. Mathew S, Davies M, Lund R, Saab G, Hruska KA (2006) Function and effect of bone morphogenetic protein-7 in kidney bone and the bonevascular links in chronic kidney disease. Eur J Clin Invest 36 Suppl 2 43-50.

72. Barreto DV, BarretoFde C, Carvalho AB, Cuppari L, Draibe SA, et al. (2008) Association of changes in bone remodeling and coronary calcification in hemodialysis patients: a prospective study. American journal of kidney diseases: the official journal of the National Kidney Foundation 52: 1139-1150.

73. Adragao T, Herberth J, Monier-Faugere MC, Branscum AJ, Ferreira A, et al. (2009) Low bone volume--a risk factor for coronary calcifications in hemodialysis patients. Clin J Am SocNephrol 4: 450-455,

74. Rodriguez-Garcia M, Gomez-Alonso C, Naves-Diaz M, Diaz-Lopez JB, Diaz-Corte C, et al. (2009) Vascular calcifications, vertebral fractures and mortality in haemodialysis patients. Nephrology, dialysis, transplantation: official publication of the European Dialysis and Transplant Association - European Renal Association 24: 239-246.

75. Coen G, Ballanti P, Mantella D, Manni M, Lippi B, et al. (2009) Bone turnover, osteopenia and vascular calcifications in hemodialysis patients. A histomorphometric and multislice CT study. Am J Nephrol 29: 145-152.

76. Silverman SL (2010) Sclerostin. J Osteoporos 2010: 941419.

77. Baron R, Rawadi G (2007) Targeting the Wnt/beta-catenin pathway to regulate bone formation in the adult skeleton. Endocrinology 148: 2635-2643.

78. Wei W, Zeve D, Suh JM, Wang X, Du Y, et al. (2011) Biphasic and dosage-dependent regulation of osteoclastogenesis by $\hat{\mathrm{I}}^{2}$-catenin. Mol Cell Biol 31: 4706-4719.

79. Viaene L, Behets GJ, Claes K, Meijers B, Blocki F, et al. (2013) Sclerostin: another bone-related protein related to all-cause mortality in haemodialysis? Nephrology, dialysis, transplantation: official publication of the European Dialysis and Transplant Association - European Renal Association 28: 3024-3030.
80. Surendran K, Schiavi S, Hruska KA (2005) Wnt-dependent beta-catenin signaling is activated after unilateral ureteral obstruction, and recombinant secreted frizzled-related protein 4 alters the progression of renal fibrosis. Journal of the American Society of Nephrology: JASN 16: 2373-2384.

81. Hampson G, Edwards S, Conroy S, Blake GM, Fogelman I, et al. (2013) The relationship between inhibitors of the Wntsignalling pathway (Dickkopf-1(DKK1) and sclerostin), bone mineral density, vascular calcification and arterial stiffness in post-menopausal women. Bone 56: 42-47.

82. Pinzone JJ, Hall BM, Thudi NK, Vonau M, Qiang YW, et al. (2009) The role of Dickkopf-1 in bone development, homeostasis, and disease. Blood 113: 517-525.

83. Poole KE, van Bezooijen RL, Loveridge N, Hamersma H, Papapoulos SE, et al. (2005) Sclerostin is a delayed secreted product of osteocytes that inhibits bone formation. FASEB J 19: 1842-1844.

84. Caira FC, Stock SR, Gleason TG, McGee EC, Huang J, et al. (2006) Human degenerative valve disease is associated with up-regulation of low-density lipoprotein receptor-related protein 5 receptor-mediated bone formation. Journal of the American College of Cardiology 47: 1707-1712.

85. Shao JS, Cheng SL, Pingsterhaus JM, Charlton-Kachigian N, Loewy AP, et al. (2005) Msx2 promotes cardiovascular calcification by activating paracrine Wnt signals. J Clin Invest 115: 1210-1220.

86. Zhu D, Mackenzie NC, Millán JL, Farquharson C, MacRae VE (2011) The appearance and modulation of osteocyte marker expression during calcification of vascular smooth muscle cells. PLoS One 6: e19595.

87. Devarajan-Ketha H, Craig TA, Madden BJ, Robert Bergen H 3rd, Kumar $\mathrm{R}$ (2012) The sclerostin-bone protein interactome. BiochemBiophys Res Commun 417: 830-835.

88. Drake MT, Srinivasan B, Mödder UI, Peterson JM, McCready LK, et al. (2010) Effects of parathyroid hormone treatment on circulating sclerostin levels in postmenopausal women. J ClinEndocrinolMetab 95: 5056-5062.

89. Doman-Garcia P, Carrillo-Lopez N, Fernandez-Martin JL, Naves-Diaz M, Ruiz-Torres MP, et al. (2010) High phosphorus diet induces vascular calcification, a related decrease in bone mass and changes in the aortic gene expression. Bone 46: 121-128.

90. Drüeke TB, Lafage-Proust MH (2011) Sclerostin: just one more player in renal bone disease? Clin J Am SocNephrol 6: 700-703.

91. Mödder UI, Hoey KA, Amin S, McCready LK, Achenbach SJ, et al. (2011) Relation of age, gender, and bone mass to circulating sclerostin levels in women and men. J Bone Miner Res 26: 373-379.

92. Garcia-Martin A, Rozas-Moreno P, Reyes-Garcia R, Morales-Santana S, Garcia-Fontana B, et al. (2012) Circulating levels of sclerostin are increased in patients with type 2 diabetes mellitus. The Journal of clinical endocrinology and metabolism 97: 234-241.

93. Schulz E, Arfai K, Liu X, Sayre J, Gilsanz V (2004) Aortic calcification and the risk of osteoporosis and fractures. J ClinEndocrinolMetab 89: 4246-4253.

94. Atkins GJ, Rowe PS, Lim HP, Welldon KJ, Ormsby R, et al. (2011) Sclerostin is a locally acting regulator of late-osteoblast/preosteocyte differentiation and regulates mineralization through a MEPE-ASARMdependent mechanism. Journal of bone and mineral research 26: $1425-1436$. 